\title{
The Relationship between Oil and Financial Markets in Emerging Economies: The Significant Role of Kazakhstan as the Oil Exporting Country
}

\begin{abstract}
This study evaluated volatility spillovers among oil price, volatility index and a pool of the credit default swaps for emerging market economies. A special role was ascribed to the time-varying interdependencies and connectedness from the perspectives of Kazakhstan, an oil exporting country. The result shows that Kazakhstan may be more resistant to the volatility, which originated from the other emerging countries. However, Kazakhstan is more sensitive to the global "fear index barometer" of volatility index and oil price volatility. The results might be appealing for portfolio diversification strategies because Kazakhstan's credit default swaps are in the low oil dependency regime.
\end{abstract}

Keywords: Volatility spillovers, frequency connectedness, generalized autoregressive score models, time-varying copula, emerging markets. 


\section{Introduction}

Hydrocarbon markets and crude oil prices, in particular, are often investigated for their influence and connectedness with stock markets, currency markets, and the overall economic performance from the perspectives of oil-importing, oil-exporting, developed and emerging economies. For example, Basher et al. (2012) employed the vector autoregressive (VAR) framework to study emerging markets' stocks and the responses of their exchange rates to oil demand and supply shocks. A similar analysis was also conducted by Wang et al. (2013) but in the context of oilexporting and oil-importing economies. The case of China has been particularly investigated by Broadstock \& Filis (2014), some European oil importing countries were studied by Cunado \& de Gracia (2014), while the United States stocks were examined by Angelidis et al. (2015) and Gozgor and Demir (2017). Other notable works, which can be allocated to a similar research domain, are the investigations conducted by Basher et al. (2018), Boldanov et al. (2016), Gozgor et al. (2015), Kang et al. (2015), and Salisu \& Isah (2017). The list is by no means complete but is arguably sufficient to highlight that finance and economics professionals persistently monitor progress in oil markets, the affiliated stocks, currencies, other financial assets, and instruments. Yet, reviewing relevant literature, it can be noted that Kazakhstan's hydrocarbon export contributions to the markets are acknowledged but how this key economic activity positions Kazakhstan to the external shocks emerging in the oil markets has been poorly addressed and thus, not well documented in the academic literature. ${ }^{1}$

Motivated to fulfil this country-specific gap, the present study focused on the 5-year credit default swaps (CDS) for Kazakhstan (KAZ), Russia (RUS), South Africa (SA) and Turkey (TUR) as well as on the volatility index (VIX) and BRENT spot oil prices. Given that the daily CDS for Kazakhstan's sovereign debt have been available from the 30th of November 2005 in Bloomberg ${ }^{2}$, this paper is convenient for representative estimations similar to the general CDS, whether country or institution-specific, the study of Atil et al. (2016), Bekiros et al. (2018), Christoffersen et al. (2017), Creal \& Tsay (2015), Fabozzi et al. (2016), Fei et al. (2017), and Yu (2017) among others. By employing time-varying copulas for exploratory correlation analysis complemented with the volatility spillover framework of Barunik \& Krehlik (2018), the obtained results aim to spot the diversification potential with Kazakhstan's debt instruments. Our findings are valuable, since Yang et al. (2018) has reported the overall rising dependency in the CDS of developed countries and emerging economies and suggest gold as a standard risk-heaven measurement and diversification instrument of sovereign credit risks, while diverse financial audiences may be interested in other less conventional investment options at their disposal. Moreover, given Basher et al.'s (2018) report on the financial performance of low-volatility - stock investments and high volatility - debt investment strategy in the context of oil exporting countries, Kazakhstan's sovereign securities may be especially attractive under the investment restrictions with Russian debt instruments. Indeed, under the economic sanctions scenario for one country and Basher et al.'s (2018) strategy consideration in the high market volatility states as a result of such economic restrictions, alternative treasury instruments for countries with similar credit rankings, debt to

\footnotetext{
${ }^{1}$ See e.g., investigation of Basher et al. (2012) or more recent and also persuasive investigation again by Basher et al. (2018) in particular, highlighting that Kazakhstan's stock market development is not at a sufficient stage as per Basher et al.'s (2018) criteria for it to be included in the pool of their investigated countries.

${ }^{2}$ For example, in Kuwait similar daily CDS are available from October 4, 2016; in Norway from January 31, 2008; in Saudi Arabia from April 27, 2017; yet these countries take the deserved spot in the relevant investigations, despite the fact that Norway and Kuwait export volumes are similar to Kazakhstan. For details, see Basher et al. (2018).
} 
gross domestic product ratios and overall similarities of the economies may represent valuable investment opportunities. ${ }^{3}$ To the best of our knowledge, this is the first paper in the literature that investigated the time evolving connectedness of Kazakhstan's credit risks with other emerging economies, oil and volatility index.

The rest of the paper is organised as follows. Section 2 explains the data and employed methodology, Section 3 discusses the findings and Section 4 provides the concluding remarks.

\section{Data and Methodology}

For our preliminary dependency analysis and the subsequent volatility computations for spillover investigations, we employ the time-varying filtering framework of the Generalized Autoregressive Score (GAS) models of Creal et al. (2013). For simplicity of the analysis, we select a parsimonious GAS $(1,1)$ specification, which is outlined as follows:

$\mathbf{f}_{t+1}=\kappa+A s_{t}+B \mathbf{f}_{t}$

where $\mathbf{f}_{t}$ is a vector of time-varying parameters, $s_{t}=\mathbf{S}_{t} \frac{\partial L_{t}}{\partial \mathbf{f}_{t}}$ for $\mathbf{S}_{\boldsymbol{t}}=\mathbf{S}\left(\mathbf{f}_{t}, F_{t-1} ; \gamma\right), L_{t}=$ $\log \mathbf{p}\left(x_{t} \mid F_{t-1} ; \mathbf{f}_{t}, \gamma\right)$ for $\log$-returns marginals and $L_{t}=\log \mathbf{p}\left(U_{t} \mid F_{t-1} ; \mathbf{f}_{t}, \gamma\right)$ for bivariate copula respectively, $\gamma$ denotes any static parameters and $F_{t-1}$ available information set. Essentially, $L_{t}(\cdot)$ is the logarithm of the conditional PDF, $\mathbf{p}(\cdot)$, and $\mathbf{S}_{t}(\cdot)$ is a positive scaling matrix usually set as $\mathbf{S}_{t}(\cdot)=I_{t}(\cdot)^{-1}$ (see Creal et al. (2013) and Harvey (2013) for details and other common scaling options).

We obtain the log-returns ( $P$ represents the price/index $)$, as such:

$x_{t}=\log \left(\frac{P_{t}}{P_{t-1}}\right) 100$

Table 1 presents a brief description of the common characteristics of all variables.

[Insert Table 1 around here]

Since the log-returns are heavy-tailed, lightly skewed, located around zero and exhibit volatility clustering for our univariate GAS $(1,1)$ applications, we pragmatically choose $\mathbf{p}(\cdot)$ specification of the location-scale skewed Student's $t$ distribution of Fernandez \& Steel (1998), where the scale parameter follows the dynamics given in equation (1) and other parameters remain static over the period of estimation to account for the observed properties. Then, volatilities for spillovers investigation are outlined by the logarithm of the conditional variance, $\log \left(\hat{\sigma}_{t}^{2} \mid F_{t-1} ; \mathbf{f}_{t}, \gamma\right)$, while the obtained innovations after GAS filtering, $\hat{\varepsilon}_{l, t}$, are transformed, as follows:

$\mathbf{P}(x)=\frac{1}{T+1} \sum_{t=1}^{T} \mathbf{1}\left(\hat{\varepsilon}_{\iota, t} \leq x\right)$ for $\iota=1,2$

3 See Tarr \& Jensen (2012) and World Bank (2015) for detailed discussions on the features of KAZ and RUS economies, International Monetary Fund (IMF) database for the specific debt to GDP ratios and Bloomberg terminal for the credit rankings. 
to the Probability Integral Transforms, $\hat{u}_{\iota, t} \in \widehat{U}_{t}$, for the brief copula dependency analysis ensuring uniformity characteristics of these pseudo-observations. We employ $\mathbf{p}(\cdot)$ specification of the standard bivariate Gaussian copula for which the closed form of $s_{t}$ for equation (1) is available from Creal et al. (2013), making it very convenient for our time-varying dependency analysis. That is,

$S_{t}=\frac{2}{1-\rho_{t}^{2}}\left[\boldsymbol{\Phi}^{-1}\left(\hat{u}_{1, t}\right)^{2} \boldsymbol{\Phi}^{-1}\left(\hat{u}_{2, t}\right)^{2}-\rho_{t}-\rho_{t} \frac{\boldsymbol{\Phi}^{-1}\left(\widehat{u}_{1, t}\right)^{2}+\boldsymbol{\Phi}^{-1}\left(\widehat{u}_{2, t}\right)^{2}-2}{1+\rho_{t}^{2}}\right]$

Where $\boldsymbol{\Phi}^{-1}(\cdot)$ is the quantile function of the standard normal and $\rho_{t}$ is the correlation parameter defining the Gaussian copula. ${ }^{4}$ Shortly, the approach adopted is the most standard semiparametric framework to dynamic copula estimations, where both copula and marginal distributions are directly related to the GAS framework (see Patton, 2012, 2013 for a comprehensive review of the dynamic copula practices). All copula and parameters necessary for volatility estimation of the log-returns in Table 1 are provided in Table 2 . Thereafter, we compute the frequencies of 5 and 200 days to assess short and "restricted" long-term Kazakhstan connectedness with other emerging economies, oil price, and the VIX. This is identical to the oil markets' very representative example of Ferrer et al. (2018). We also explained the approximation of the obtained volatility spillovers in Appendix I. ${ }^{5}$

[Insert Table 2 around here]

\section{Results and Discussion}

First, it is worthwhile to inspect raw CDS, which are illustrated in Figure 1 and are split into two periods. In the snapshot encompassing the events associated with the financial crisis, we observe that KAZ has the highest score, although the evolution of TUR, preceding this financial turbulence is noteworthy to highlight. Also, it should be noted that KAZ seems to follow the path of RUS, fulfilling a general expectation usually formed from the macroeconomic profiles of these two countries. KAZ, however, is still arguably above RUS in the period of financial crisis, suggesting that Kazakhstan's sovereign debt securitization is viewed as riskier under similar pressures in international markets. This could be as a result of the lower development state of its economy and financial markets. Meanwhile, a snapshot encompassing a more recent evolution of the considered CDS, points out changes in the debt perceptions of these emerging economies. In the events of more recent oil prices downfalls, on the market's oversupply, KAZ once again follows RUS, but the latter has a higher score. Moving further in time, the path of KAZ begins to

\footnotetext{
${ }^{4}$ Note that in the GAS framework, to ensure that parameters are always within their expected domains, appropriate increasing invertible functions (e.g. logarithmic, logistic, etc.) are used. See Creal et al. (2013) for details.

${ }^{5}$ Before moving into our discussion of the findings, it must be highlighted that the outlined spillover estimation framework is due to Barunik \& Krehlik (2018) and seems to be gaining popularity in relevant literature (see e.g., Corbet et al., 2018; Lau et al., 2017; Tiwari et al., 2018). Spillover estimation by Barunik \& Krehlik (2018) is closely related to the framework of Diebold \& Yilmaz (2012) and can be regarded as an extension of the latter. In this study, we specifically investigated the net time-varying volatility spillovers for Kazakhstan with a rolling window of 200 and a forecasting horizon of 100 daily observations, once again following the work of Ferrer et al. (2018). The illustrated rolling net volatility spillovers are computed using VAR(2) plus constant model, which has been cross-validated for different lag-lengths (up to five) variations to yield different net spillover outputs, as originally used and suggested by Barunik \& Krehlik (2018) to address potential concerns over the validity of estimations. It is important to note that there are no notable differences in the net spillovers reported and identified for different specifications of the VAR model.
} 
notably diverge from other considered CDS. Moreover, in 2018, the lowest credit risk in the pool of considered countries was suggested. The recovery of oil markets and their peaks in 2018 may suggest a stable "cash inflow" to Kazakhstan and perhaps less pressure from the "quantitative tightening" as in South Africa, "liberal" monetary policy as in the Turkish economy, and economic sanctions as in Russia. It may be valid to argue different sets of credit risks for Kazakhstan and other countries in our pool and therefore, valuable features of Kazakhstan's treasury bills under the modern international trade/finance development phase for emerging markets.

\section{[Insert Figure 1 around here]}

Dynamic dependencies in Figure 1 are also in line with the above initial analysis. The correlations of KAZ with other countries can be noted as rising and are the highest in the financial crisis. Then, although the dependencies remain relatively high during the entire period of estimations, it is easy to pick up a diminishing trend in KAZ co-movements within other countries, which reaches its bottom in 2018 and is notably below its unconditional levels. ${ }^{6}$ Evaluating the KAZBRENT pair dynamic correlation, it is necessary to note low and high dependency patterns. In fact, following the guidelines of Fei et al. (2017), we fit the Markov switching normal copula to unpack these two states of KAZ relationship with the price of oil. Figure 1 illustrates the obtained regime probabilities confirming our observation when analysing time-varying copula correlations. In fact, a small gain in the Markov switching copula log-likelihood value over the simple dynamic GAS copula, given the number of parameters for both specifications, is notable, suggesting the appropriateness of the low and high regimes observation. ${ }^{7}$ Our KAZ-BRENT regimes unpack what has been observed in the recent oil market downfalls of 2014-2015 for CDS of other exporting countries, including Russia, Mexico, Qatar, and Bahrain (Shahzad et al., 2017). Though, from our observations KAZ, falls into the high oil dependency regime only in 2015, similar to UAE and Saudi Arabia as identified by Shahzad et al. (2017). We also find that if a country accumulates wealth and fiscal stability on the previous oil market highs as shown by Wegener et al. (2016) for Norway, Saudi Arabia, Russia and Qatar among others, its CDS spread may be more stable in the coming oil downturn cycles, since after the recent downfalls, KAZ becomes low oil dependent faster than after the financial crisis, although oil markets secured notably higher price levels after the financial crisis quicker than in the more recent oil lows.

\section{[Insert Figure 2 around here]}

The obtained net volatility spillovers are illustrated in Figure 2. The obtained spillovers point out the higher connectedness in the long-term frequency as may be expected for the CDS indices which approximate sovereign debt credit risks that are usually less risky than CDS for stocks, although financial crisis and oil volatility also depicts some short-term spillovers which are worth mentioning over KAZ. As may be expected for an oil exporting country, KAZ is mainly a net receiver of the turbulence originating in the hydrocarbon markets. Moreover, the magnitude of such spillovers is quite notable, persistent and high, especially during the financial crisis. VIX

\footnotetext{
${ }^{6}$ Refer to Fei et al. (2017) and Yang et al. (2018) for other relevant dependency levels.

7 We also experimented with fitting a Student's t copula to observe if a functional form allowing for tail dependencies would provide appealing likelihood gains but considering the little gain in likelihood value and increased number of parameters, our normal Markov switching copula results seem to be sufficient and appropriate for exploratory analysis preceding the volatility spillovers investigation provided further.
} 
developments have an influence on KAZ which are also worth highlighting. In particular, it is notable how KAZ absorbs VIX turbulence on the concerns reflected in the S\&P 500 over the Chinese stock market abrupt corrections in 2015, which also contributed to the oil demand uncertainties of already oversupplied hydrocarbon markets. On the oil price bottoms of 2016, KAZ absorbed RUS volatility as well as the Turkish "coup attempt" instabilities followed by the sharp lira devaluations and consequent potential of Turkey default fears on its foreign currency denominated debt. It should be noted that all these events coincide with the high oil dependency regime for KAZ. As per SA, KAZ is the main transmitter of volatility originating in the oil and other emerging markets. After oil markets show signs of recovery, KAZ enters into the low oil dependency regime and becomes indifferent to the higher credit risks in RUS, SA and TUR indices, which in 2018 can be mainly articulated due to the looming pressure from "sanctions", "quantitative tightening", and interest rate decisions under an abruptly devalued currency, respectively. Therefore, in addition to the conclusions by Pavlova et al. (2018) for a pool of the oil exporting countries, we find that in the more recent cycle of the oil and developing markets, the debt securitization of KAZ is lower than for other considered CDS and may be attractive for the investors interested in realising potential of the recovering oil markets, ${ }^{8}$ since KAZ seems to be less sensitive to other volatility sources we consider if it is in the low oil dependency regime.

Finally, we fit the GAS time-varying Student's $t$ copula specification, as reported in Table 2 and though, we observed some notable gains in the log-likelihoods, suggesting a better fit, the obtained time-varying correlation paths were not found different from what was used in the exploratory positions of KAZ in the considered data set as illustrated in Figure 1. On the other hand, analysing the reported shape parameters of the Student's $t$ copula density showed that there is a good potential describing tail dependencies which are beyond the scope of our work. ${ }^{9}$

\section{Concluding Remarks}

This paper analysed a small pool of CDS for Kazakhstan, Russia, South Africa and Turkey. The divergences of Kazakhstan's CDS index from of countries were considered and proceeds in conducting volatility spillovers investigation for Kazakhstan credit risks. The obtained results confirm conclusions of Wegener et al. (2016) that higher oil prices improve fiscal stability of oil exporting countries (when compared to the importers, e.g. TUR \& SA) and that there can be heterogeneous responses within CDS of oil exporters themselves due to geopolitical factors as also concluded by Boldanov et al. (2016), however, not only between developed and developing oil exporting economies (e.g. between Norway and Russia or Canada and Russia as in Boldanov et al.), but also among developing and integrated oil exporting economies (e.g. RUS and KAZ). Although there are other risks to be considered, this indicates that there may be opportunities for investments and portfolio diversification with Kazakhstan's debt instruments. Moreover, Kazakhstan and its CDS, in particular, may be informative and attractive for inclusion in the full-

\footnotetext{
8 See for example, Jonathan Wheatley. Investors scramble for Kazakhstan's euro-denominated bonds. Financial Times, November 16, 2018. Available at: https://www.ft.com/content/df3ff3a4-e677-11e88a85-04b8afea6ea3

${ }^{9}$ Although we do not go beyond the provided correlation analysis due to brevity reasons, our intrinsic dependency investigation is beyond what is common prior to the spillover estimations of Barunik \& Krehlik (2018) (see e.g., Ferrer et al., 2018). We experimented with the Markov switching models to unpack regimes in other reported dependencies, but the findings were inconclusive. In addition, more elaborated GAS specifications provide volatility estimates leading to the visually indistinguishable correlation and reported spillover results.
} 
scale study of empirical CDS determinants similar to that of Yang et al. (2018) by expanding our Kazakhstan oriented investigation.

\section{References}

Angelidis, T., Degiannakis, S., \& Filis, G. (2015). US stock market regimes and oil price shocks. Global Finance Journal, 28, 132-146.

Atil, A., Bradford, M., Elmarzougui, A., \& Lahiani, A. (2016). Conditional dependence of US and EU sovereign CDS: A time-varying copula-based estimation. Finance Research Letters, $19,42-53$.

Barunik, J., \& Krehlik, T. (2018). Measuring the frequency dynamics of financial connectedness and systemic risk. Journal of Financial Econometrics, 16(2), 271-296.

Basher, S. A., Haug, A. A., \& Sadorsky, P. (2012). Oil prices, exchange rates and emerging stock markets. Energy Economics, 34(1), 227-240.

Basher, S. A., Haug, A. A., \& Sadorsky, P. (2018). The impact of oil-market shocks on stock returns in major oil-exporting countries. Journal of International Money and Finance, 86, 264-280.

Bekiros, S., Hammoudeh, S., Jammazi, R., \& Nguyen, D. K. (2018). Sovereign bond market dependencies and crisis transmission around the Eurozone debt crisis: a dynamic copula approach. Applied Economics, 47, 5031-5049.

Boldanov, R., Degiannakis, S., \& Filis, G. (2016). Time-varying correlation between oil and stock market volatilities: Evidence from oil-importing and oil-exporting countries. International Review of Financial Analysis, 48, 209-220.

Broadstock, D. C., \& Filis, G. (2014). Oil price shocks and stock market returns: New evidence from the United States and China. Journal of International Financial Markets, Institutions and Money, 33, 417-433.

Catania, L., Boudt, K., \& Ardia, D. (2018). Gas: Generalized autoregressive score models [Computer software manual]. Retrieved from https://CRAN.R-project.org/package=GAS (R package version 0.2.8)

Christoffersen, P., Jacobs, K., Jin, X., \& Langlois, H. (2017). Dynamic dependence and diversification in corporate credit. Review of Finance, 22(2), 521-560.

Corbet, S., Meegan, A., Larkin, C., Lucey, B., \& Yarovaya, L. (2018). Exploring the dynamic relationships between cryptocurrencies and other financial assets. Economics Letters, 165, 28-34.

Creal, D., Koopman, S. J., \& Lucas, A. (2013). Generalized autoregressive score models with applications. Journal of Applied Econometrics, 28(5), 777-795.

Creal, D., \& Tsay, R. S. (2015). High dimensional dynamic stochastic copula models. Journal of Econometrics, 189(2), 335-345.

Cunado, J., \& de Gracia, F. P. (2014). Oil price shocks and stock market returns: Evidence for some European countries. Energy Economics, 42, 365-377.

Diebold, F. X., \& Yilmaz, K. (2012). Better to give than to receive: Predictive directional measurement of volatility spillovers. International Journal of Forecasting, 28(1), 57-66.

Fabozzi, F. J., Giacometti, R., \& Tsuchida, N. (2016). Factor decomposition of the Eurozone sovereign CDS spreads. Journal of International Money and Finance, 65, 1-23.

Fei, F., Fuertes, A.-M., \& Kalotychou, E. (2017). Dependence in credit default swap and equity markets: Dynamic copula with Markov-switching. International Journal of Forecasting, 33(3), 662-678. 
Fernandez, C., \& Steel, M. F. (1998). On Bayesian modelling of fat tails and skewness. Journal of the American Statistical Association, 93(441), 359-371.

Ferrer, R., Shahzad, S. J. H., Lopez, R., \& Jareno, F. (2018). Time and frequency dynamics of connectedness between renewable energy stocks and crude oil prices. Energy Economics, $76,1-20$.

Gozgor, G. \& Demir, E. (2017). Excess stock returns, oil shocks, and policy uncertainty in the U.S. Economics Bulletin, 37(2), 741-755.

Gozgor, G., Natanelov, V. \& Van Huylenbroeck, G. (2015). The impact of the global crisis of 2008-09 on the relationship between stock markets and oil price in the BRIC countries. Indian Journal of Finance, 9(4), 7-20.

Harvey, A. C. (2013). Dynamic models for volatility and heavy tails: with applications to financial and economic time series (Vol. 52). Cambridge: Cambridge University Press.

Kang, W., Ratti, R. A., \& Yoon, K. H. (2015). Time-varying effect of oil market shocks on the stock market. Journal of Banking \& Finance, 61 (S2), S150-S163.

Krehlik, T. (2018). Frequencyconnectedness: Spectral decomposition of connectedness measures [Computer software manual]. Retrieved from https://cran.rproject.org/web/packages/frequencyConnectedness (R package version 0.2.1)

Lau, M. C. K., Vigne, S. A., Wang, S., \& Yarovaya, L. (2017). Return spillovers between white precious metal ETFs: The role of oil, gold, and global equity. International Review of Financial Analysis, 52, 316-332.

Patton, A. (2012). A review of copula models for economic time series. Journal of Multivariate Analysis, 110, 4-18.

Patton, A. (2013). Copula methods for forecasting multivariate time series. In Handbook of economic forecasting (Vol. 2, pp. 899-960). Amsterdam: Elsevier.

Pavlova, I., de Boyrie, M. E., \& Parhizgari, A. M. (2018). A dynamic spillover analysis of crude oil effects on the sovereign credit risk of exporting countries. The Quarterly Review of Economics and Finance, 68, 10-22.

R Core Team. (2018). R: A language and environment for statistical computing [Computer software manual]. Vienna, Austria. Retrieved from https://www.R-project.org/

Salisu, A.A., \& Isah, K. O. (2017). Revisiting the oil price and stock market nexus: A nonlinear panel ARDL approach. Economic Modelling, 66, 258-271.

Shahzad, S. J. H., Naifar, N., Hammoudeh, S., \& Roubaud, D. (2017). Directional predictability from oil market uncertainty to sovereign credit spreads of oil-exporting countries: Evidence from rolling windows and crossquantilogram analysis. Energy Economics, 68, 327-339.

Tarr, D., \& Jensen, J. (2012). Assessment of Costs and Benefits of the Customs Union for Kazakhstan. World Bank Report, No. 74356-KZ. Washington, D.C.: World Bank.

Tiwari, A. K., Cunado, J., Gupta, R., \& Wohar, M. E. (2018). Volatility spillovers across global asset classes: Evidence from time and frequency domains. The Quarterly Review of Economics and Finance, 70, 194-202.

Wang, Y., Wu, C., \& Yang, L. (2013). Oil price shocks and stock market activities: Evidence from oil-importing and oil-exporting countries. Journal of Comparative Economics, 41(4), 1220-1239.

Wegener, C., Basse, T., Kunze, F., \& von Mettenheim, H. J. (2016). Oil prices and sovereign credit risk of oil producing countries: an empirical investigation. Quantitative Finance, 16 (12), 1961-1968. 
World Bank. (2015). Kazakhstan Trade Report: Improving the Trade Policy Framework. Washington, D.C.: World Bank.

Yang, L., Yang, L., \& Hamori, S. (2018). Determinants of dependence structures of sovereign credit default swap spreads between G7 and BRICS countries. International Review of Financial Analysis, 59, 19-34.

$\mathrm{Yu}$, S. (2017). Sovereign and bank interdependencies evidence from the CDS market. Research in International Business and Finance, 39, 68-84.

Table 1

Descriptive Statistics for the Specified 5-year-CDS, VIX, and BRENT Log-returns

\begin{tabular}{cccccccccc}
\hline Date & Log-returns & T & Mean & Std. Dev. & Skewness & Kurtosis & LB(12) & LB $^{2}(12)$ & AH(12) \\
\hline $01.11 .05-30.11 .18$ & KAZ & 3157 & 0.0011 & 3.7141 & -0.0825 & 16.1134 & 0.0001 & 0.0000 & 0.0000 \\
$01.11 .05-30.11 .18$ & RUS & 3157 & 0.0269 & 3.8897 & 0.6735 & 14.2244 & 0.0000 & 0.0000 & 0.0000 \\
$01.11 .05-30.11 .18$ & TUR & 3157 & 0.0209 & 3.3288 & 0.3564 & 9.4612 & 0.0000 & 0.0000 & 0.0000 \\
$01.11 .05-30.11 .18$ & SA & 3157 & 0.0463 & 3.5178 & 0.4703 & 11.0281 & 0.0000 & 0.0000 & 0.0000 \\
$01.11 .05-30.11 .18$ & VIX & 3157 & 0.0052 & 7.5987 & 1.0199 & 9.6294 & 0.0000 & 0.0000 & 0.0000 \\
$01.11 .05-30.11 .18$ & BRENT & 3157 & -0.0004 & 2.1894 & 0.2619 & 10.0609 & 0.0574 & 0.0000 & 0.0000 \\
\hline
\end{tabular}

Notes: $\mathrm{LB}(12)$ and $\mathrm{LB}^{2}(12)$ are 12th order Ljung-Box no serial correlation probabilities in log-returns and squared demeaned log-returns respectively; $\mathrm{AH}(12)$ is 12th order Lagrange Multiplier no autocorrelation, normality, and homoscedasticity probabilities. All data has been obtained from Bloomberg. 
Table 2

Estimated Parameters for Dependences Investigation and Volatility Computation

\begin{tabular}{|c|c|c|c|c|c|c|c|c|c|c|}
\hline & & & & & & & $B$ & d.f. & sk. & $-L$ \\
\hline \multirow{12}{*}{$G A S_{t}$} & $\mathrm{KAZ}_{\mu}$ & -0.1364 & $(0.0443)$ & & & & & \multirow{2}{*}{4.0021} & \multirow{2}{*}{0.9907} & \multirow{2}{*}{-7828.92} \\
\hline & $\mathrm{KAZ}_{\sigma}$ & 0.0409 & $(0.0098)$ & 0.0939 & $(0.0099)$ & 0.964 & $(0.0084)$ & & & \\
\hline & $\mathrm{RUS}_{\mu}$ & -0.1174 & $(0.0528)$ & & & & & \multirow{2}{*}{5.0446} & \multirow{2}{*}{1.0243} & \multirow{2}{*}{-8174.53} \\
\hline & $\mathrm{RUS}_{\sigma}$ & 0.0511 & $(0.0133)$ & 0.0787 & (0.0099) & 0.958 & $(0.0108)$ & & & \\
\hline & $\mathrm{TUR}_{\mu}$ & -0.0532 & $(0.0478)$ & & & & & \multirow{2}{*}{5.1373} & \multirow{2}{*}{1.0364} & \multirow{2}{*}{-7798.20} \\
\hline & $\mathrm{TUR}_{\sigma}$ & 0.0339 & $(0.0094)$ & 0.0624 & $(0.0079)$ & 0.9689 & $(0.0084)$ & & & \\
\hline & $\mathrm{SA}_{\mu}$ & -0.0617 & $(0.0475)$ & & & & & \multirow{2}{*}{4.7561} & \multirow{2}{*}{1.0184} & \multirow{2}{*}{-7845.67} \\
\hline & $\mathrm{SA}_{\sigma}$ & 0.0552 & $(0.0134)$ & 0.0874 & $(0.0102)$ & 0.9508 & $(0.0116)$ & & & \\
\hline & $\operatorname{VIX}_{\mu}$ & -0.1681 & $(0.1071)$ & & & & & \multirow{2}{*}{4.7646} & \multirow{2}{*}{1.1554} & \multirow{2}{*}{-10488.3} \\
\hline & $\mathrm{VIX}_{\sigma}$ & 0.2179 & $(0.0422)$ & 0.0933 & (0.0108) & 0.8894 & $(0.0214)$ & & & \\
\hline & $\mathrm{BRENT}_{\mu}$ & 0.0219 & $(0.0301)$ & & & & & \multirow{2}{*}{7.0804} & \multirow{2}{*}{0.9747} & \multirow{2}{*}{-6474.97} \\
\hline & $\mathrm{BRENT}_{\sigma}$ & 0.0033 & $(0.0015)$ & 0.0274 & $(0.0037)$ & 0.9953 & $(0.0021)$ & & & \\
\hline \multirow{5}{*}{$G A S_{\text {normal }}^{\text {cop }}$} & KAZ-RUS $_{\rho}$ & 0.0028 & $(0.0017)$ & 0.0142 & $(0.0014)$ & 0.9868 & $(0.0010)$ & & & -919.73 \\
\hline & KAZ-TUR $_{\rho}$ & 0.0034 & $(0.0019)$ & 0.0191 & $(0.0018)$ & 0.9831 & $(0.0017)$ & & & -749.72 \\
\hline & $\mathrm{KAZ}-\mathrm{SA}_{\rho}$ & 0.0060 & $(0.0024)$ & 0.0174 & $(0.0025)$ & 0.9796 & (0.0029) & & & -716.80 \\
\hline & KAZ-VIX $\rho$ & 0.0037 & $(0.0018)$ & 0.0056 & $(0.0021)$ & 0.9877 & $(0.0037)$ & & & -111.52 \\
\hline & $\begin{array}{l}\text { KAZ- } \\
\text { BRENT }_{\rho}\end{array}$ & -0.0015 & $(0.0009)$ & 0.0118 & $(0.0025)$ & 0.9855 & $(0.0035)$ & & & -95.27 \\
\hline \multirow{6}{*}{$G A S_{t}^{c o p}$} & KAZ-RUS $_{\rho}$ & 0.0020 & $(0.0016)$ & 0.0092 & $(0.0012)$ & 0.9889 & $(0.0009)$ & 6.9446 & & -973.28 \\
\hline & KAZ-TUR $_{\rho}$ & 0.0024 & $(0.0017)$ & 0.011 & $(0.0015)$ & 0.9863 & $(0.0014)$ & 7.1314 & & -794.13 \\
\hline & $\mathrm{KAZ}-\mathrm{SA}_{\rho}$ & 0.0056 & $(0.0022)$ & 0.0118 & (0.0018) & 0.9831 & $(0.0023)$ & 6.7075 & & -773.59 \\
\hline & KAZ-VIX $_{\rho}$ & 0.0047 & $(0.0021)$ & 0.0046 & $(0.0020)$ & 0.9871 & $(0.0043)$ & 14.5619 & & -118.99 \\
\hline & $\begin{array}{l}\text { KAZ- }^{-} \\
\text {BRENT }_{\rho}\end{array}$ & -0.0013 & $(0.0009)$ & 0.0101 & $(0.0022)$ & 0.9865 & $(0.0032)$ & 20.3406 & & -99.47 \\
\hline & & \multicolumn{2}{|c|}{$\rho_{1}$} & \multicolumn{2}{|c|}{$\rho_{2}$} & $\pi_{H H}$ & $\pi_{L L}$ & d.f.1 & d.f.2 & \\
\hline \multirow{5}{*}{ normal } & KAZ-RUS & 0.6411 & $(0.0088)$ & & & & & & & -831.25 \\
\hline & KAZ-TUR & 0.5814 & $(0.0102)$ & & & & & & & -647.5 \\
\hline & KAZ-SA & 0.5697 & $(0.0105)$ & & & & & & & -616.00 \\
\hline & KAZ-VIX & 0.2559 & $(0.0168)$ & & & & & & & -106.07 \\
\hline & $\begin{array}{l}\text { KAZ- } \\
\text { BRENT }\end{array}$ & -0.1937 & $(0.0169)$ & & & & & & & -59.87 \\
\hline \multirow{5}{*}{ Student } & KAZ-RUS & 0.6578 & $(0.0102)$ & & & & & 5.5165 & & -899.70 \\
\hline & KAZ-TUR & 0.5998 & $(0.0116)$ & & & & & 5.6891 & & -707.85 \\
\hline & KAZ-SA & 0.5935 & $(0.0119)$ & & & & & 5.4013 & & -692.39 \\
\hline & KAZ-VIX & 0.2567 & $(0.0172)$ & & & & & 13.9118 & & -114.44 \\
\hline & $\begin{array}{l}\text { KAZ- } \\
\text { BRENT }\end{array}$ & -0.1965 & $(0.0178)$ & & & & & 15.6931 & & -66.57 \\
\hline $\begin{array}{c}\text { RS- } \\
\text { normal }\end{array}$ & \multirow{2}{*}{$\begin{array}{l}\text { KAZ- } \\
\text { BRENT }\end{array}$} & -0.3526 & $(0.0262)$ & -0.0103 & $(0.0282)$ & 0.9984 & 0.9982 & & & -97.02 \\
\hline $\begin{array}{c}\text { RS- } \\
\text { Student }\end{array}$ & & -0.3451 & $(0.0278)$ & -0.0056 & $(0.0300)$ & 0.9986 & 0.9982 & 15.5212 & 528.5498 & -100.05 \\
\hline
\end{tabular}

Note: d.f. denotes degrees of freedom and sk. estimated skewness, respectively. 


\section{Figure 1}

Raw 5-year-CDS for the Specified Countries and Kazakhstan CDS Log-returns Time-varying Dependences for the CDS of Russia, South Africa, Turkey, and the VIX as well as Kazakhstan CDS and BRENT
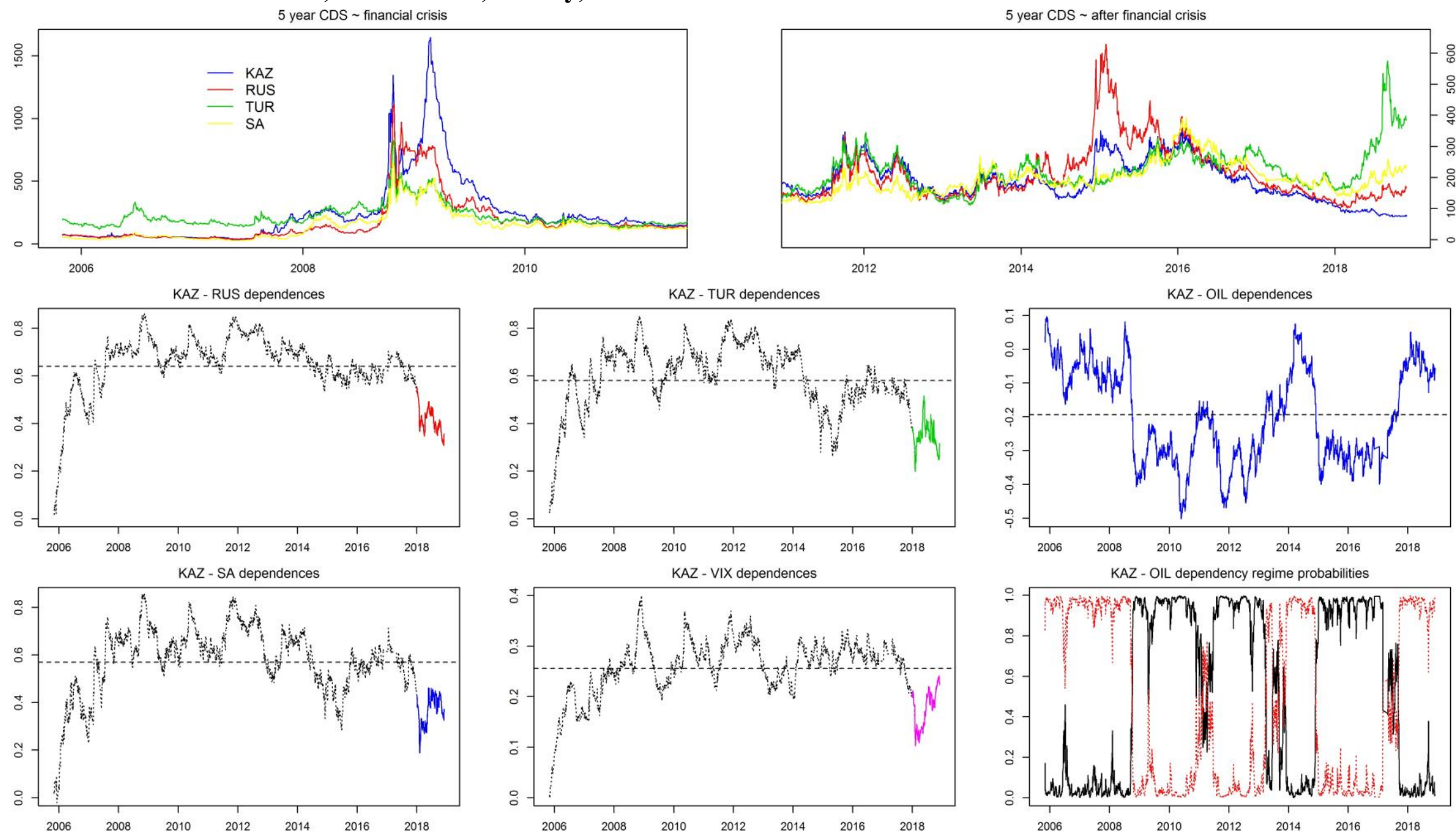

Notes: Log-returns time-varying dependences with associated hidden. Markov regimes for the low and high dependencies respectively. - - - ; horizontal lines indicate time unconditional dependence and - - - ;; probabilities for the low oil dependency regime. 
Figure 2

Frequency Decomposed Method of Barunik \& Krehlik (2018) for Net Volatility Spillovers for Kazakhstan CDS Pairs
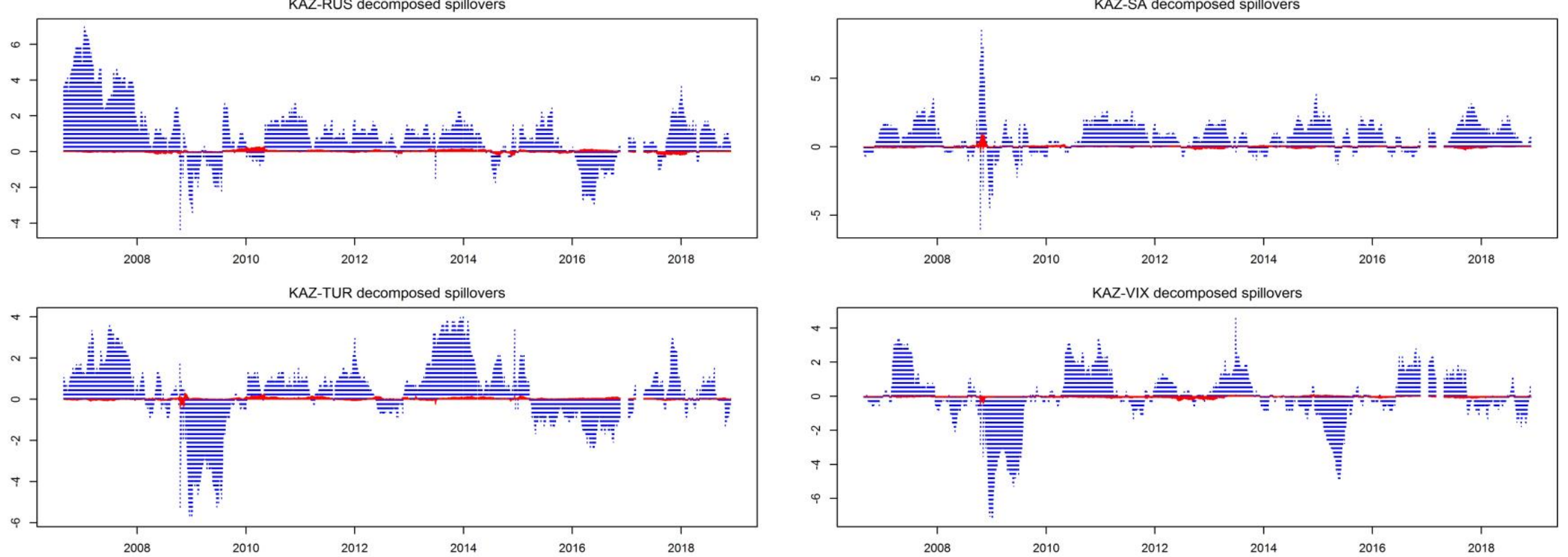

KAZ-OIL decomposed spillovers

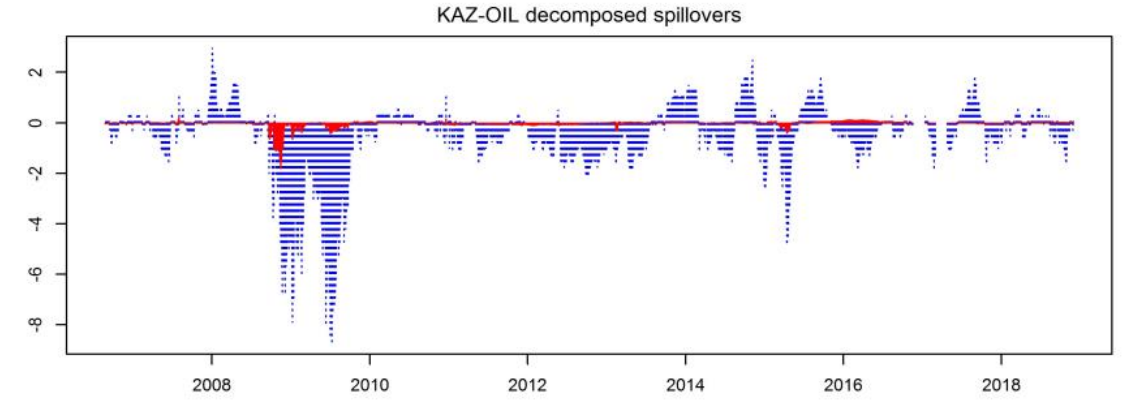

Notes: Positive values indicate Kazakhstan's transmission of volatility across other variables under consideration and negative Kazakhstan's reception/accumulation of the external volatility pressures respectively. Blue area highlights connectedness within the 200 days' range, while the red area outlines volatility connectedness within the 5 days' range. 


\section{Appendix I. Approximation of the Obtained Volatility Spillovers}

Let us consider a following VAR model:

$Y_{t}=\Omega(\boldsymbol{L}) Y_{t}+\epsilon_{t}$

of $n$ variables and $k$ lags, where $Y_{t}$ is a vector of endogenous variables, $\Omega(\boldsymbol{L})=\sum_{h} \Omega_{h} \boldsymbol{L}^{h}$ is a symmetric polynomial matrix of $k$ th order lag coefficients, $\boldsymbol{L}$ lag operator and $\epsilon_{t}$ are white noise errors with covariance matrix $\Sigma$. Note that it is the $\log$ transformations of the time conditional variance in our specific case. Then, under the covariance stationarity assumption:

$Y_{t}=\mho(\boldsymbol{L}) \epsilon_{t}=\sum_{i=1}^{\infty} \mho_{i} \epsilon_{t-i}+\epsilon_{t}$

where $\mho(\boldsymbol{L})$ denotes a recursively computed symmetric matrix of infinite lag polynomials in the above VAR moving average representation, forecast error variance of a variable can be decomposed to the shocks from other variables as such:

$\theta_{i j}(H)=\frac{\sigma_{j j}^{-1} \sum_{h=0}^{H}\left(\left[\mho_{h} \Sigma\right]_{i j}\right)^{2}}{\sum_{h=0}^{H}\left(\mho_{h} \Sigma \mho_{h}^{\prime}\right)_{i i}}$,

where $\sigma_{j j}$ is the $j$ th element of the $\Sigma$ diagonal, insured to sum to one over the selected forecast horizon $H$. Pairwise $\theta_{i, j}(H)$ decomposition in (A2) can be regarded as a degree of connectedness from $i$ to $j$ over the forecasting horizon $H$, which in turn can become a further decomposed connectedness measure over the desired time frequency bands. It may be achieved with a frequency response function by Fourier transformation of $\mho_{h}$ coefficients, setting $i=\sqrt{-1}$, given by $\mho(\exp (-i h \omega))=$ $\sum_{h=0}^{\infty} \exp (-i h \omega) \mho_{h}$, where $\omega$ outlines some pre-determined frequency bands. If the variance distribution of $Y_{t}$ over the frequency bands in $\omega$ is outlined with a power spectrum as follows:

$K_{Y}(\omega)=\mho(\exp (-i h \omega)) \Sigma \mho(\exp (i h \omega))$

measure in (A3) can be reformulated to approximate $i \rightarrow j$ type connectedness at a particular $\omega$ frequency band (e.g. short, medium or long-term) given by

$\theta_{i j}(\omega)=\frac{\sigma_{j j}^{-1} \sum_{h=0}^{\infty}(\mho[\exp (-i h \omega)] \Sigma)_{i j}^{2}}{\sum_{h=0}^{\infty}[\mho(\exp (-i h \omega)) \Sigma \mho(\exp (i h \omega))]_{i i}}$ 
Again measure in (A5) may be necessary forcing to sum to unity and for the frequency band $b=(a, d): a, d \in(-\pi, \pi), a<d$ it is given by $\theta(b)_{i j} \int_{a}^{d} \theta_{i j}(\omega) d \omega$. Given that our scope and analysis are Kazakhstan oriented, computed net pairwise connectedness between the volatility of KAZ and other variables in Table 1 are outlined by

$C_{i j}^{b}=\theta_{j i}(b)-\theta_{i j}(b)$ 